Sharif University of Technology
Scientia Iranica
Transactions E: Industrial Engineering
SCIENTIA
I RAN I C A

\title{
Multi-objective sustainable supply chain with deteriorating products and transportation options under uncertain demand and backorder
}

\author{
M. Sepehri* and Z. Sazvar \\ Graduate School of Management and Economics, Sharif University of Technology, Tehran, Iran.
}

Received 8 September 2014; received in revised form 28 June 2015; accepted 15 October 2016

\author{
KEYWORDS \\ Sustainable supply \\ chain; \\ Deteriorating \\ products; \\ Transportation; \\ Possibilistic \\ programming; \\ Green supply.
}

\begin{abstract}
Supply chain sustainability, with economic, environmental, and social values, has gained attention in both academia and industry. For deteriorating and seasonal products, like fresh produce, the issues of timely supply and disposal of the deteriorated products are of great concern. This paper is to develop a possibilistic mathematical model, solved after linearizing the non-linear statements, and to propose a new replenishment policy for a centralized Sustainable Supply Chain (SSC) for deteriorating items. Different transportation vehicle options, which produce various pollution and greenhouse gas (GHG) levels, are considered. Several variables such as the end-customer demand, the partial backordered ratio, and the deterioration rate are uncertain. Deterioration occurs for in-stock inventories and during transportation. The solution provides the optimum transportation modes and routes, and the inventory policy by finding a balance between financial, environmental, and social criteria.

(C) 2016 Sharif University of Technology. All rights reserved.
\end{abstract}

\section{Introduction}

"A supply chain is a system of organizations, people, technology, activities, information, and resources involved in moving a product or service from supplier to customer" [1]. Adding the 'green' concept to the 'supply chain' concept creates a new paradigm, where the supply chain will have a direct relation to the environment [2]. The green SCM concept is further developed into sustainable SCM to include social features of the supply chain as well as environmental and economic aspects.

There has been growing concern about the environmental and social footprints of business operations. People are conscious of the world's environmental problems, such as pollution, global warming, toxic

*. Corresponding author. Tel.: 02166165856 ;

Fax: 021 66022759

E-mail address: sepehri@sharif.edu (M. Sepehri) substance usage, and non-renewable resources [2]. The majority of papers in supply chain network design focus on economic performance. Recent studies have considered environmental dimensions. There is a gap in quantitative models of social factors with environmental and economic impacts [3].

Uncertainty is an inherent attribute of supply chains, which affects the supply chain's performance and complexity. Numerous methods exist for quantitative description of supply chain uncertainty in the literature, most generally involving interval analysis [4], possibilistic and fuzzy sets methods [5], stochastic programming methods [6], etc.

Transportation is a major factor in deteriorating products supply chain, as deterioration and economic and environmental factors depend on the distance and condition of product transportation. To reduce purchase costs and attract a larger base of customers, retailers, such as WalMart, Home Depot, and Costco, are constantly seeking suppliers with lower prices and 
finding them at greater distances from their distribution centers and stores [7].

This paper employs many of the recent aspects of deteriorating products SCM. It simultaneously considers economic, environmental, and social objectives; transportation and route options; uncertain demand; deterioration and backorder ratios; and non-linear sale price discount. Deterioration can occur both in in-stock inventories and during transportation in the model. Deterioration during transportation is a function of transportation type (truck vs. airplane, refrigerated vs. individually packed, etc.) and transportation routes. A possibilistic approach is used to find the optimum solution for a centralized supply chain, where the leftover product is disposed of for a given amount of cost or profit. These distinct features are used simultaneously to provide a holistic model and reach an applied solution. The main research question is the impact of the social factors introduced in the model, combined with the economic and environmental impacts. A fresh produce center in Tehran, Iran, was used to gather data and test the model.

In the next two sections, various relevant aspects of SCM used in our research, i.e. Sustainable Supply Chains (SSC), deteriorating products, and fresh produce, are reviewed. Section 4 presents the problem description, including notations and assumptions, followed by the sections on the mathematical model, solution approach, numerical analysis, and conclusions.

\section{Literature review}

The literature review is presented in two sub-sections: We first review some of the main studies on SSC, and then assess some major research on replenishment policies for deteriorating products.

\subsection{Sustainable supply chain}

The Brundtland Report [8] underlined the importance of sustainable development and called for "a better life for everyone without destroying the natural resources for future generations". Since then, the concept of sustainability has been broadened to include Planet, People, and Profit [9]. It may be argued that "Sustainable Development" and "Sustainability" are not essentially the same. Accordingly, the former is concerned with processes while the latter is considered as a state. These two terms are frequently used interchangeably in the literature without highlighting the differences [10]. In this paper and most other studies in the supply chain literature, the concept used is sustainability.

Organizations are increasingly assimilating sustainability into their SCM practices. Although the motivations of individual organizations may vary, key objectives generally include an interest in achieving sustainable streams of products, services, information, and funds to provide maximum value for involved stakeholders [11].

According to [12], Sustainable SCM (SSCM) is "the management of material, information, and capital flows as well as cooperation among companies along the supply chain while integrating goals from all three dimensions of sustainable development, i.e., economic, environmental, and social, which are derived from customer and stakeholder requirements."

Table 1 shows an illustrative sample of recent papers in the area of SSC. While this is by no means a representative sample of all existing research in the literature, it is sufficient to illustrate the gaps and deficiencies in the current research. For a more comprehensive review of studies in the field of SSCs, interested readers are referred to [13]. According to Table 1 , the related literature can be characterized in three groups based on the direction of material flows:

i) Forward Logistic (FL): Many researchers have considered the sustainability concept in forward logistic processes (conventional logistic) where after procuring from suppliers, raw materials are converted to finished goods at manufacturer sites and, subsequently, transferred to customers via distribution centers to fulfill their demands [14]. Brandenburg et al. [13] provide a review of 134 papers on quantitative, formal models that addressed sustainability aspects in forward supply chains;

ii) Reverse Logistic (RL)/Backward Logistics (BL): These studies consider the flow of used or returned products from the customers back to the collection centers for reusing, remanufacturing, recovering, disposal, etc;

iii) Closed-loop supply chains: These studies, such as $[3,5,15]$, consider a supply chain network by integrating the forward processes with the backward processes.

In addition, many SSCM quantitative models developed for uncertain conditions come from various sources like demand, capacities, costs, etc. Based on Sazvar et al. [6], there are four main approaches for considering uncertainty in the decision-making process: robust optimization, stochastic programming, fuzzy programming, and stochastic dynamic programming.

As Table 1 shows, very few studies take into account multiple sustainability dimensions as compared to studies developed in green supply chains (considering economic and environmental criteria). Many studies present real-world cases from the pharmaceutical, medical, glass, food, etc. industries to demonstrate the applicability of their developed models. However, limited research has explicitly addressed an important category of products called deteriorating items. In the 
Table 1. Illustrative sample of research on sustainable replenishment.

\begin{tabular}{|c|c|c|c|c|c|c|c|c|}
\hline Year & Author(s) & $\begin{array}{l}\text { Modelling } \\
\text { approach }\end{array}$ & $\begin{array}{c}\text { Characteristics: } \\
\text { Forward/ } \\
\text { backward }\end{array}$ & $\begin{array}{c}\text { Application } \\
\text { in } \\
\text { real cases }\end{array}$ & $\begin{array}{l}\text { Uncertain } \\
\text { parameters }\end{array}$ & $\begin{array}{l}\text { Economic } \\
\text { criteria }\end{array}$ & $\begin{array}{l}\text { Environ. } \\
\text { criteria }\end{array}$ & $\begin{array}{c}\text { Social } \\
\text { criteria }\end{array}$ \\
\hline 2010 & $\begin{array}{c}\text { Pishvaee } \\
\text { Torabi \& [5] }\end{array}$ & $\begin{array}{c}\text { Possibilistic } \\
\text { prog. }\end{array}$ & $\begin{array}{l}\text { Forward/ } \\
\text { backward }\end{array}$ & - & $\begin{array}{c}\text { Costs, } \\
\text { capacities, } \\
\text { demands, } \\
\text { rates of } \\
\text { return products }\end{array}$ & $\begin{array}{l}\text { Min total } \\
\text { costs }\end{array}$ & - & $\begin{array}{c}\text { Total } \\
\text { delivery } \\
\text { tardiness }\end{array}$ \\
\hline 2014 & $\begin{array}{c}\text { Validi } \\
\text { et al. [20] }\end{array}$ & $\begin{array}{l}\text { Mixed } \\
\text { integer } \\
\text { prog. }\end{array}$ & Forward & $\begin{array}{l}\text { Food } \\
\text { industry }\end{array}$ & - & $\begin{array}{l}\text { Min total } \\
\text { costs }\end{array}$ & $\begin{array}{l}\text { Min. } \mathrm{CO}_{2} \\
\text { emission }\end{array}$ & \\
\hline 2011 & $\begin{array}{l}\text { Pishvaee, } \\
\text { et al. [21] }\end{array}$ & $\begin{array}{c}\text { Robust } \\
\text { possibilistic } \\
\text { prog. }\end{array}$ & Forward & $\begin{array}{l}\text { Medical } \\
\text { industry }\end{array}$ & $\begin{array}{c}\text { Costs, demand, } \\
\text { capacities }\end{array}$ & $\begin{array}{l}\text { Min total } \\
\text { costs }\end{array}$ & - & $\begin{array}{c}\text { Max } \\
\text { social } \\
\text { responsibility }\end{array}$ \\
\hline 2014 & $\begin{array}{l}\text { Sazvar } \\
\text { et al. [6] }\end{array}$ & $\begin{array}{l}\text { 2-stage } \\
\text { stock } \\
\text { prog. }\end{array}$ & Forward & $\begin{array}{c}\text { Pharmaceutical } \\
\text { industry }\end{array}$ & Demand & $\begin{array}{l}\text { Min total } \\
\text { costs }\end{array}$ & $\begin{array}{l}\text { Min. GHG } \\
\text { emission }\end{array}$ & - \\
\hline 2011 & $\begin{array}{l}\text { Wang } \\
\text { et al. [22] }\end{array}$ & $\begin{array}{l}\text { Mixed } \\
\text { integer } \\
\text { prog. }\end{array}$ & Forward & $\begin{array}{l}\text { A procurement } \\
\text { center }\end{array}$ & - & $\begin{array}{l}\text { Min total } \\
\text { cost }\end{array}$ & $\begin{array}{l}\text { Min. } \mathrm{CO}_{2} \\
\text { emission }\end{array}$ & - \\
\hline 2015 & $\begin{array}{c}\text { Das and } \\
\text { Posinasetti } \\
{[15]}\end{array}$ & $\begin{array}{c}\text { Mixed integer } \\
\text { program, } \\
\text { goal prog. }\end{array}$ & $\begin{array}{l}\text { Forward/ } \\
\text { backward }\end{array}$ & - & $\begin{array}{l}\text { Returned } \\
\text { products to the } \\
\text { retailer } \\
\text { (scenario } \\
\text { based) }\end{array}$ & $\begin{array}{c}\text { Max total } \\
\text { profit }\end{array}$ & $\begin{array}{c}\text { 1-min. spent } \\
\text { energy -Min. } \\
\text { harmful } \\
\text { emission }\end{array}$ & - \\
\hline 2010 & $\begin{array}{l}\text { El-Sayed } \\
\text { et al. [23] }\end{array}$ & $\begin{array}{l}\text { Multi-stage } \\
\text { stochastic } \\
\text { prog. }\end{array}$ & $\begin{array}{l}\text { Forward/ } \\
\text { backward }\end{array}$ & - & Demand & $\begin{array}{l}\text { Max total } \\
\text { profit }\end{array}$ & - & - \\
\hline 2014 & $\begin{array}{l}\text { Devika } \\
\text { et al. [3] }\end{array}$ & $\begin{array}{l}\text { Mixed } \\
\text { integer } \\
\text { prog. }\end{array}$ & $\begin{array}{l}\text { Forward/ } \\
\text { backward }\end{array}$ & $\begin{array}{c}\text { Glass } \\
\text { industry }\end{array}$ & - & $\begin{array}{l}\text { Min total } \\
\text { costs }\end{array}$ & $\begin{array}{l}\text { Min. } \mathrm{CO}_{2} \\
\text { emission }\end{array}$ & $\begin{array}{l}\text { Max social } \\
\text { responsibility }\end{array}$ \\
\hline 2010 & $\begin{array}{l}\text { Jamshidi } \\
\text { et al. }[24]\end{array}$ & $\begin{array}{l}\text { Mixed } \\
\text { Integer } \\
\text { Prog. }\end{array}$ & Forward & - & Demand & $\begin{array}{l}\text { Min total } \\
\text { costs }\end{array}$ & $\begin{array}{c}\text { Min produced } \\
\text { dangerous } \\
\text { gases }\left(\mathrm{NO}_{2},\right. \\
\mathrm{CO}, \text { volatile } \\
\text { organic } \\
\text { (VOCs)) }\end{array}$ & A \\
\hline
\end{tabular}

next sub-section, in Table 2, the literature on these types of products is reviewed.

\subsection{Deteriorating products}

Deterioration of goods is a common phenomenon. Pharmaceuticals, blood, flowers, fruits, vegetables, dairy, meat, and foods are just a few examples. Perishable models have been widely studied in recent years. The literature on perishable product SCM has skyrocketed. Deterioration is defined as the damage, spoilage, vaporization, dryness, etc. of items [16]. Continuously deteriorating items suffer loss in quantity or in quality. This is distinct from obsolescence, or sudden death, where items lose their value because of rapid change in technology, introduction of a new product, or going out of fashion [17]. Ghare and Schrader [16] were among the first to study deteriorating products and developed an inventory model 
Table 2. Illustrative sample of research on deteriorating products replenishment.

\begin{tabular}{|c|c|c|c|c|c|c|c|c|}
\hline \multirow[b]{2}{*}{ Year } & \multirow[b]{2}{*}{ Author } & \multirow[b]{2}{*}{$\begin{array}{l}\text { Solution } \\
\text { approach }\end{array}$} & \multirow[b]{2}{*}{$\begin{array}{l}\text { Demand } \\
\text { function }\end{array}$} & \multirow[b]{2}{*}{$\begin{array}{l}\text { Deterioration } \\
\text { function }\end{array}$} & \multirow[b]{2}{*}{$\begin{array}{l}\text { Inventory } \\
\text { system }\end{array}$} & \multicolumn{2}{|l|}{ Shortage } & \multirow[b]{2}{*}{$\begin{array}{l}\text { Objective } \\
\text { function }\end{array}$} \\
\hline & & & & & & $\begin{array}{c}\text { PB: } \\
\text { partial } \\
\text { backorder }\end{array}$ & $\begin{array}{l}\text { Planning } \\
\text { horizon }\end{array}$ & \\
\hline 2014 & $\begin{array}{l}\text { Kim } \\
\text { et al. [26] }\end{array}$ & Exact-simulation & Constant & Inventory dependent & FOQ & Backorder & Infinite & Min cost \\
\hline 2011 & $\begin{array}{l}\text { Wang } \\
\text { et al. [33] }\end{array}$ & Heuristic & Constant & Time dependent & FOQ/FOI & $\mathrm{NO}$ & Infinite & Min cost \\
\hline 2011 & $\begin{array}{l}\text { Wee } \\
\text { et al. [34] }\end{array}$ & Exact & Constant & Constant & FOQ/FOI & NO & Finite & Max profit \\
\hline 2010 & $\begin{array}{l}\mathrm{He} \\
\text { et al. [35] }\end{array}$ & Exact & $\begin{array}{c}\text { Time } \\
\text { dependent }\end{array}$ & Constant & FOQ/FOI & NO & Finite & Min cost \\
\hline 2009 & $\begin{array}{c}\text { Wee and } \\
\text { Chung [36] }\end{array}$ & Exact & Constant & Constant & FOI & $\mathrm{NO}$ & Infinite & Min cost \\
\hline 2008 & Liao [37] & Exact & Constant & Constant & FOQ & NO & Infinite & Min cost \\
\hline 2008 & Urban [38] & Heuristic & $\begin{array}{l}\text { Inventory } \\
\text { dependent }\end{array}$ & $\begin{array}{c}\text { Non-linear } \\
\text { time dependent } \\
\text { holding cost }\end{array}$ & FOQ/FOI & NO & Infinite & Max profit \\
\hline 2007 & Dye [39] & Heuristic & $\begin{array}{c}\text { Price } \\
\text { dependent }\end{array}$ & Time dependent & FOQ & P.B & Infinite & Max profit \\
\hline 2007 & $\begin{array}{c}\text { Mahata \& } \\
\text { Goswam [40] }\end{array}$ & Exact & $\begin{array}{l}\text { A fuzzy } \\
\text { number }\end{array}$ & $\begin{array}{l}\text { A constant } \\
\text { deterioration } \\
\text { rate }+ \text { A fuzzy } \\
\text { holding cost }\end{array}$ & FOI & $\mathrm{NO}$ & Infinite & Min cost \\
\hline 2005 & $\begin{array}{c}\text { Dye \& } \\
\text { Ouyang [41] }\end{array}$ & Exact & $\begin{array}{l}\text { Inventory } \\
\text { dependent }\end{array}$ & Constant & FOI/FOQ & P.B. & Infinite & Max profit \\
\hline 1998 & Luo $[42]$ & Numerical & $\begin{array}{c}\text { Price and } \\
\text { advertisement } \\
\text { dependent }\end{array}$ & Weibull & FOQ & Lost sale & Infinite & Max profit \\
\hline 1982 & Weiss [43] & Exact & $\begin{array}{l}\text { 1- Constant, } \\
\text { 2-Poisson }\end{array}$ & $\begin{array}{c}\text { Non-linear } \\
\text { time dependent } \\
\text { holding cost }\end{array}$ & FOQ/FOI & $\mathrm{NO}$ & Infinite & Min cost \\
\hline
\end{tabular}

for exponentially decaying inventory. Amorim et al. [18] studied the effects of concurrent optimization of production and distribution for perishable products. Prastacos [19] published a survey of blood inventory management.

Bakker et al. [25] reviewed over 200 papers published in the last decade on deteriorating inventory systems. In Table 2, a summary of the main related research is presented. The types of demand, shortage, and deterioration functions for each study are reported. More details about some of the main assumptions, such as inventory system (Fixed Order
Quantity (FOQ)/Fixed Order Interval (FOI)), solution approach, planning horizon, and objective function types are also presented.

From Tables 1 and 2, it can be seen that little research deals with deteriorating products in SSCs in comparison with the research on products with unlimited lifetime. Sazvar et al. [6] developed a stochastic replenishment model in a centralized green supply chain for deteriorating items, with inventory and transportation costs and the environmental impact under uncertain demand. They found, because of the recycling of deteriorated items, the environmental 
impact of deteriorating items was more significant than that of non-deteriorating ones. Kim et al. [26] studied a closed-loop supply chain where Returnable Transport Items (RTIs) were applied to ship deteriorating goods from the supplier to the buyer. Then, empty RTIs were collected at the buyers and returned to the supplier.

In summary, the main issues, like considering social criteria, deterioration during transportation, and effect of transportation paths, as well as vehicle types on deterioration process, are significantly challenging in the real world. However, to the best of our knowledge, less attention has been paid to quantitative studies.

\subsubsection{Fresh produce}

Fresh produce (fruits, flowers, and vegetables) is a fast growing segment of the economy, and exporting and importing of fresh produce are common phenomena [27]. The success factors in fresh produce SCM include continuous investment (despite tight margins), volume growth (providing confidence in the future), improvement of measurement and control of costs (in the pursuit of gains in efficiency), and innovation (the level of service and the way of doing business with key customers) [28].

The challenge in managing fresh produce is that product value deteriorates significantly over time at rates that are highly temperature- and humiditydependent. The scope of most published studies is the post-harvest supply chain [38]. Agricultural issues like seed production and growing have not been explored. A decision about supply chain involves a choice between responsiveness and efficiency [28]. Blackburn et al. [29] found that supply chain should be responsive in the early stages and efficient in later stages.

For fresh produce, a retailer procures from a supplier a quantity of a fresh product, which must then be transported to reach the target market. The retailer has to make an appropriate effort to preserve freshness of the product, and may pay higher costs for better transportation [28]. In practice, it is common to offer deteriorated items at a discount price. In supermarkets, items near the expiration date are marked down to influence buying behavior the consumer [30].

Shukla and Jharkharia [31] presented a literature review of the fresh produce SCM, with processes from production to consumption. The main interest in fresh produce SCM is consumer satisfaction and revenue maximization, while post-harvest waste reduction is a secondary objective. Inaccuracy in demand forecasting, demand and supply mismatch, lesser integrated approach, etc. are of concern. Though social and environmental factors in fresh produce supply chain are major concerns, very little research exists at this time on developing a comprehensive SSCM model for these products.

\section{Research gaps}

Worldwide grocery retailers' sales in 2012 exceeded $\$ 1,000$ billion. Deteriorating products, such as fresh produce, dairy, and meat, account for more than a third of these sales [32]. Managing SCM of deteriorating products is progressively becoming more important. Today's customers request greater product diversity and price. Thus, more deteriorating products tend to exceed the best-before date, while demand and price per product tend to be less predictable. In addition to normal SCM costs (ordering, transportation, holding, and shortage), deteriorating items impose extra costs on the system.

Today, for many corporations, sustainability is a major factor for competitiveness and survival. The environmental factors, for deteriorating product manufacturers and retailers, not only come from transportation factors and GHG emissions, but also are a factor of disposal of spoiled and unused products. The social factors need to be considered equally and separately as parts of sustainability, too. Social factors, in particular for seasonal and highly volatile demand products, are becoming strategic issues. Firms can no longer easily hire and fire employees at will, ignore their welfare and training, impose unreasonable hours and working conditions, etc. For products traded multinationally, local workers need specific treatment, by law and by social responsibility principles, so that work would not be sent offshore just because of cost or trade considerations. For deteriorating products, such as fresh produce, there is a mismatch between supply and demand, encouraging increasing imports and exports.

The motivation for this research comes not only from a lack of suitable work in the literature, but also from the growing importance of the above gaps in practice. Deteriorating items increasingly affect the lives of employers and consumers in the developed and developing countries, and are exceedingly creating issues in economic, environmental, and social fronts for corporations and politicians.

This research considers the sustainable supply chain planning problem for deteriorating products in a multi-period environment under: i) uncertain demand and ii) a price-discount scheme, and by considering iii) sustainability criteria, particularly social and humanresource related ones; iv) different transportation vehicle types as well as dependency of on-the-way deterioration rate to the vehicle types; v) different paths for transportation depending on on-the-way deterioration rate to the path types; and vi) various costs such as shortage, disposal, and human resource costs.

Reviewing the existing literature shows that though a great deal of research has been conducted on these types of problems, to the best of our knowledge, no holistic system has been developed to cover all 

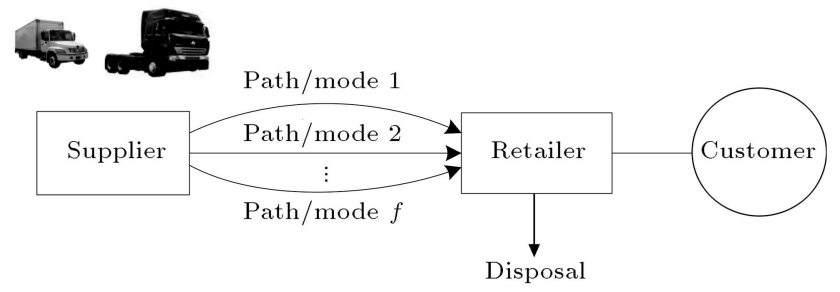

Figure 1. A schematic of the considered supply chain.

aspects of the above description. A broad range of such studies has been devoted to some of its aspects separately or to their specific combinations. Therefore, there is a gap between practical and theoretical contributions of deteriorating product's SCM, and the aim of this paper is to bridge this gap by considering all the mentioned aspects in a centralized SSC.

\section{Problem description}

A centralized forward supply chain provides a deteriorating product, as shown in Figure 1. The supply chain consists of three kinds of entities: a supplier, a retailer, and customers. The planning horizon is finite and consists of multiple periods. At each period, a quantity order is supplied by the supplier and shipped to the retailer in order to respond to end-customer's demand. Because of deterioration characteristics of the product, if inventory is left at the end of a period at the retailer site, $\tilde{\theta}$ percent of it should be disposed. The end-customer's demand $(\tilde{D})$ and deterioration rate of on-hand inventories $(\tilde{\theta})$ are considered as uncertain parameters.

Since the demand rate $(\tilde{D})$ and deterioration rate $(\tilde{\theta})$ are uncertain, shortage can occur at each period, which may be partially backordered. In this way, at each period, $\tilde{\beta}$ ratio of unfulfilled demands (if exists) can wait up to the next period, while the other $1-\tilde{\beta}$ ratio will be lost. $\tilde{\beta}$ is assumed to be uncertain, too.

The supplier, providing the product, should ship it to the retailer. There are several transportation vehicle options available at the supplier site. Each one is characterized by its capacity, transportation cost, GHG emission, and the deterioration of on-the-way product. Each type of transportation vehicles has its technical specifications, which affect the product deterioration rate during transportation. Thus, the deterioration rate of on-the-way product is variable and depends on the vehicle type.

As in Figure 1, there are also various paths (or transportation modes) from the supplier to the retailer. In the real world, various types of vehicle and different paths are available to send goods from suppliers to retailers. The vehicle types/paths have a considerable influence on each product's transportation cost, amount of GHG emission, and deterioration rate of product. For example:
- More modern and efficient transportation vehicles keep the product healthier and generate less GHG, but they incur higher costs;

- Sometimes, transportation by ship is faster and cheaper, but results in more disposals because of humidity. In contrast, overland paths cause fewer disposals, but are more expensive and slower;

- Sometimes, using vans is more rapid and more expensive, and thus, it results in low product disposal in comparison with using trucks.

In summary, there are two sources of deterioration: i) deterioration rate of on-hand inventory at retailer warehouse $(\tilde{\theta})$ and ii) deterioration rate of onthe-way products $\left(\tilde{\eta}_{v f}\right)$, which is affected by vehicles type $(v)$ as well as transportation paths/mode features $(f)$.

In many real cases, the selling price depends on the sale quantity. In this problem, the selling price $(p r)$ is non-linearly dependent on the sale quantity by the following function:

$$
p r=\left\{\begin{array}{cc}
p r_{1} & S A_{0} \leq S_{t}<S A_{1} \\
p r_{2} & S A_{1} \leq S_{t}<S A_{2} \\
\cdots & \ldots \\
p r_{m} & S A_{m-1} \leq S_{t}<S A_{m}
\end{array}\right.
$$

In Eq. (1), $S_{t}$ indicates sale in period $t$. Also, $p r_{1}>$ $p r_{2}>p r_{3}>\ldots>p r_{m}>0$ and $S A_{0}<S A_{1}<S A_{2}<$ $\ldots<S A_{m}$ are positive parameters. In other words, as the sale-quantity increases, the selling price decreases.

The objective is to find the best configuration of vehicle type, transportation path/mode, and order quantities in each period to simultaneously meet the following criteria:

i) Maximizing the total profit (an economic objective);

ii) Minimizing total GHG emissions (an environmental objective); and

iii) Minimizing human recourse variations from one period to another (a social objective).

There is a need for employees to carry out the logistic activities, including transportation and other logistic activities, throughout the supply chain. In some periods, since the forecasted customer demand is very high, the order quantity and, consequently, the amount of required logistic activities throughout the chain increase in order to respond to demand. These logistic activities are packing products at the supplier, unpacking products at the retailer, repacking products at the retailer, issuing invoices, etc. The required transportation fleet and, thus, the labor needed may also increase. In such periods, usually, the number of 
required workers is more than the number of workers available in the supply chain. In this way, either some extra labor must be hired or the supply chain managers accept leaving a part of the demands unsatisfied.

In contrast, in some periods, the forecasted demand is very low and, as a result, the order quantity and the volume of required logistic activities decrease in comparison with the previous periods. In such periods, the supply chain managers decide either to keep a number of workers inactivated or to fire them. In the production planning literature, adjusting resource levels (including human resources) to the volume of forecasted demands is called "chase strategy". Some disadvantages of this strategy are reducing job interest, decreasing the job satisfaction and job security of workers, and increasing administrative costs related to high levels of hiring and firing. In this way, variations in labor levels from one period to another can be regarded as a significant social criterion in supply chains.

The opposite of chase strategy is "leveling strategy" where a fixed number of workers are kept through all periods regardless of changes in the forecasted demands. A main disadvantage of this strategy is high level of inactivated workers in some periods. Usually, the optimal strategy is somewhere between "chase strategy" and "leveling strategy", which can be determined by the mathematical model developed in this paper by considering economic, environmental, and social criteria.

\subsection{Assumptions}

The following assumptions are also considered in developing the proposed mathematical model:

- The uncertain parameters, $\tilde{D}, \tilde{\beta}, \tilde{\theta}$, and $\tilde{\eta}_{v f}$, are fuzzy numbers;

- The retailer's initial inventory (or shortage) level, $I_{0}$ (or $B_{0}$ ), can be positive, zero, or negative;

- Human resource level consists of two components: i) required human resource for transportation, called "transportation labors", and ii) required human resource for doing other logistic activities (except transportation) through the supply chain, such as packing products at supplier, unpacking and repacking products at the retailer, etc. We have called these labors "logistic labors";

- Purchase cost $(c)$, holding cost $(h)$, backorder cost $(\gamma)$, lost sale cost $(\pi)$, and disposal cost $(S V)$ for a unit of product are given and fixed parameters;

- There is a limited number of vehicles of each type;

- The cost of disposal for each unit of product, $S V$, is defined by a multiple-breakpoint function as follows:

$$
S V=\left\{\begin{array}{lc}
S V_{1} & K_{0} \leq \text { disposal quantity }<K_{1} \\
S V_{2} & K_{1} \leq \text { disposal quantity }<K_{2} \\
\cdots & \quad \ldots \\
S V_{p} & K_{p-1} \leq \text { disposal quantity }<K_{p}
\end{array}\right.
$$

In the above function, each $S V_{i}(0 \leq i \leq p)$ is a predefined parameter that can be positive, negative, or zero depending on the case. For example, deteriorated plastics or drugs are usually sold to recycling centers and, therefore, bring money for the system. In contrast, deteriorated fruits and vegetables have to be disposed, which is cost-generating. $K_{0}<$ $K_{1}<K_{2}<\ldots<K_{p}$ are positive parameters. Finally, in Eq. (2), "disposal quantity" refers to two sources: i) on-hand inventories deteriorated in each period; and ii) on-the-way products deteriorated in each period.

\subsection{Notations}

The following notations are applied to develop the proposed model:

\section{Indices}

$t \quad$ Index of time period, $t \in\{1, \ldots, T\}$

$v \quad$ Index of transportation type,

$v \in\{1, \ldots, V\}$

$f \quad$ Index of path from supplier to retailer, $f \in\{1, \ldots, F\}$

$m \quad$ Index of sale quantity level, $m \in$ $\{1, \ldots, M\}$

$p \quad$ Index of disposal level, $p \in\{1, \ldots, P\}$

\section{General parameters}

$T \quad$ Planning horizon length

$\tilde{\theta} \quad$ Deterioration rate of in-stock

inventories

$\tilde{\beta} \quad$ Fraction of demand backordered during

a stock-out

$\tilde{D}_{t} \quad$ Demand in period $t$

$d_{f} \quad$ Distance between supplier and retailer under path/mode $f$

$C A P_{v} \quad$ Capacity of a type- $v$ vehicle (defined by unit of product)

$M A X T_{v} \quad$ Maximum number of type- $v$ vehicles available

$\tilde{\eta}_{v f} \quad$ Deterioration rate of product when it is transported by a type- $v$ vehicle through path/mode $f$

\section{Economic parameters}

$O \quad$ Fixed ordering cost for each replenishment

$O C_{t} \quad$ Ordering cost in period $t$

$C \quad$ A product unit purchase cost 
pr A product unit selling price

$h \quad$ A product unit holding cost per period

$\pi \quad$ Penalty cost of a product unit lost sale (including lost profit)

$\gamma \quad$ Backordered cost of a product unit per period

$S V \quad$ Disposal cost (or income) of a product unit

$T A_{v f} \quad$ Cost of transportation by a type- $v$ vehicle for each unit of distance through path/mode $f$

\section{Environmental parameters}

$G_{v f} \quad$ GHG emission level produced by a type-v vehicle under path $f$

GD GHG emission level produced by a unit of disposed product

\section{Social parameters}

$H T_{v} \quad$ Required labor for using a type- $v$ vehicle

$H U M \quad$ Average number of products in each period for which a worker can do the related logistic activities (excluding transportation) and prepare them to deliver to the customers

\section{Decision variables}

$I_{t} \quad$ Inventory level at the end of period $t$

$B_{t} \quad$ Shortage level at the end of period $t$

$Q_{t} \quad$ Net order quantity of period $t$ received by retailer

$\delta_{t v f} \quad$ Gross order quantity of period $t$ transported by a type- $v$ vehicle through path $f$

$\lambda_{t} \quad$ On-the-way inventories deteriorated in period $t$

$X_{t v f} \quad$ Number of type- $v$ vehicles used in path $f$ in period $t$

$H U_{t} \quad$ Number of labors required in period $t$

$S_{t} \quad$ Total sale in period $t$

$Z_{1} \quad$ Total cost of the supply chain

$Z_{2} \quad$ Total GHG produced in the supply chain

$Z_{3} \quad$ Total variations in human resource

\section{Mathematical model}

The proposed mathematical model is developed in two steps: First, it is developed in a non-linear form, and second, the equivalent linear form of the non-linear mathematical model in the previous step is developed by applying some linearization techniques.

\subsection{Non-linear mathematical model}

In terms of the above assumptions and notations, the proposed model can be formulated as follows:

$$
\begin{aligned}
& \operatorname{Max} Z_{1}=\sum_{t>0} p r . S_{t} \\
& -\left(\sum _ { t > 0 } \left(O C_{t}+C \cdot \sum_{v, f} \delta_{t v f}+h \cdot I_{t}\right.\right. \\
& +(1-\tilde{\beta}) \cdot \pi \cdot B_{t}+\tilde{\beta} \cdot \gamma \cdot B_{t} \\
& +\sum_{v, f}\left(T A_{v f} \cdot d_{f} \cdot X_{t v f}\right) \\
& \left.\left.+S V \cdot\left(\tilde{\theta} \cdot I_{t}+\lambda_{t}\right)\right)+C H_{t} \cdot H U_{t}\right) \text {, } \\
& \operatorname{Min} Z_{2}=\sum_{t>0}\left(\sum_{v, f}\left(G_{v f} \cdot d_{f} \cdot X_{t v f}\right)+G D \cdot\left(\tilde{\theta} \cdot I_{t}+\lambda_{t}\right)\right) \\
& \operatorname{Min} Z_{3}=\sum_{t}\left(\left|H U_{t}-H U_{(t-1)}\right|+\sum_{t, v} H T_{v} \cdot \mid \sum_{f} X_{t v f}\right. \\
& \left.-\sum_{f} X_{(t-1) v f} \mid\right)
\end{aligned}
$$

s.t.

$Q_{t}+(1-\tilde{\theta}) \cdot I_{(t-1)}-\tilde{D}_{t}-\tilde{\beta} \cdot B_{(t-1)}=I_{t}-B_{t} \quad \forall t$,

$I_{t} \cdot B_{t}=0 \quad \forall t$

$O C_{t}=\left\{\begin{array}{ll}O & Q_{t}>0 \\ 0 & \text { otherwise }\end{array} \quad \forall t\right.$

$\lambda_{t}=\sum_{v, f} \tilde{\eta} \cdot \delta_{t v f} \quad \forall t$

$Q_{t}=\sum_{v, f}\left(1-\tilde{\eta}_{v f}\right) \cdot \delta_{t v f} \quad \forall t$

$\left(H U_{t}-1\right) \leq \frac{\sum_{v, f} \delta_{t v f}}{H U M} \leq H U_{t} \quad \forall t$,

$\sum_{v, f} \delta_{t v f} \leq \sum_{v, f} C A P_{v} \cdot X_{t v f} \quad \forall t$,

$\sum_{f} X_{t v f} \leq M A X T_{v} \quad \forall v, t$

$X_{t v f}, H U_{t} \geq 0$, integer $\quad \forall t, v, f$,

$Q_{t}, \delta_{t v f}, I_{t}, \lambda_{t}, B_{t}, S_{t} \geq 0 \quad \forall t, v, f$ 
Eq. (3) represents total profit, which is total revenue minus total cost. To calculate total revenue $\left(\sum_{t>0} p r . S_{t}\right)$, the product selling price, $p r$, is defined based on Eq. (1). The total cost of system consists of ordering, procurement, holding, lost sale, backordering, transportation, disposal costs, and the wage of logistics worker, respectively. Without losing generality, it is assumed that the wages of the transportation worker are included in transportation costs of vehicles $\left(T A_{v f}\right)$. As mentioned above, disposal cost consists of two parts: cost/income of on-hand inventories deteriorated $\left(\tilde{\theta} \cdot I_{t}\right)$ and cost/income of on-the-way inventories deteriorated $\left(\sum_{v, f} \tilde{\eta}_{v f} \cdot \delta_{t v f}\right)$. Moreover, a product unit disposal cost, $S V$, follows the multiple-breakpoint function defined by Eq. (2).

Eq. (4) represents the environmental goal, which is minimization of total GHG emission from the supply chain. It consists of GHG emitted by transportation, deterioration of on-hand inventories, and deterioration of on-the-way inventories, respectively.

Eq. (5) is related to minimization of the total variation in the labor level from one period to another. It consists of two terms, variation in the required level of logistics and transportation workers, respectively. This equation is considered as a social objective function. As mentioned, changes in labor levels from one period to another not only explicitly affect costs of systems (due to the costs of hiring, firing, etc), but also have implicit and negative effects on job satisfaction, well-being, and loyalty of personnel. Defining $Z_{2}$ and $Z_{3}$ along with $Z_{1}$ leads to an economic ordering policy, which is compatible with the two main criteria of sustainability, i.e. minimization of GHG emissions (an environmental index) and labor level variations (a social index).

Constraint (6) is the inventory balance equation. Since the on-hand inventories deteriorate at rate $\tilde{\theta}$, in Eq. (6), the initial inventory of period $t$ is regarded as $(1-\tilde{\theta}) \cdot I_{(t-1)}$. Also, $\tilde{\beta}$ percent of the unfulfilled demand (shortage) in period $(t-1)$ is transferred to period $t$, which in Eq. (6) is regarded as part of that period's requirements. Constraint (7) implies that inventory and shortage levels of each period cannot take positive values concurrently. Since the ordering cost is incurred when the order quantity is positive, Constraint (8) is defined. Constraint (9) represents the equation for the on-the-way deteriorated inventories in each period. Constraint (10) means that order quantity in each period is the sum of non-perished products delivered by all transportation vehicles. Constraint (11) is defined to determine the number of required logistics workers in period $t, H U_{t}$. According to this constraint, the gross order quantity of each period, $\sum_{v, f} \delta_{t v f}$, is divided by HUM. The quotient is then rounded up to determine how many workers are needed to handle logistic activities (excluding transportation) at period $t$, i.e. $H U_{t}$. In this way, Constraint (11) explicitly and other constraints, including decision variables, $\delta_{t v f}$, implicitly affect the social criterion $\left(Z_{3}\right)$.

Constraint (12) guarantees that the quantity transported by vehicles is less than or equal to vehicle capacity. Constraint (13) shows the number of used type- $v$ vehicles is less than or equal to the available type- $v$ vehicles. Constraints (14) and (15) define variable types.

\subsection{Equivalent linear mathematical model}

There are several nonlinear expressions in the model developed above. In this section, we develop an equivalent linear mathematical model by applying some linearization techniques to find global optimum solutions by the help of some optimization packages. As stated in Section 5.1., Constraint (7) implies that $I_{t}$ and $B_{t}$ cannot be positive values concurrently. Constraint (7) can be converted to its equivalent linear form by the following two constraints:

$$
\begin{aligned}
& B_{t} \leq M \cdot N_{t} \quad \forall t, \\
& I_{t} \leq M \cdot\left(1-N_{t}\right) \quad \forall t
\end{aligned}
$$

where, in Eqs.(16) and (17), $N_{t}, t=1, \ldots, T$ are binary variables as follows:

$$
N_{t}=\left\{\begin{array}{ll}
1 & I_{t}=0 \\
0 & B_{t}=0
\end{array} \forall t\right.
$$

Generally, an ordering cost $(O)$ is incurred in a period if the order quantity at that period is positive, as in Constraint (8). The ordering cost at period $t$ can be stated as linear expression, $O \cdot V_{t}$, where $V_{t}$ are binary variables and the following constraint holds:

$$
\frac{V_{t}}{M} \leq Q_{t} \leq M . V_{t}
$$

In Constraint (19), the binary variables, $O . V_{t}$, are equal to 1 if $Q_{t}>0$, and 0 otherwise:

$$
V_{t}=\left\{\begin{array}{ll}
1 & Q_{t}>0 \\
0 & Q_{t}=0
\end{array} \forall t\right.
$$

The total sale in period $t$ and $S_{t}$ is as Eq. (21). In other words, the total sale is equal to the minimum amount of requirements $\left(D_{t}+\tilde{\beta} \cdot B_{(t-1)}\right)$ and inventories $\left(Q_{t}+(1-\tilde{\theta}) \cdot I_{(t-1)}\right)$ as follows:

$$
\begin{aligned}
& S_{t}= \min \left\{Q_{t}+(1-\tilde{\theta}) \cdot I_{(t-1)}, \tilde{D}_{t}+\tilde{\beta} \cdot B_{(t-1)}\right\} \\
&=\left\{\begin{array}{rr}
Q_{t}+(1-\tilde{\theta}) \cdot I_{(t-1)}, & \tilde{D}_{t}+\tilde{\beta} \cdot B_{(t-1)} \geq Q_{t} \\
& +(1-\tilde{\theta}) \cdot I_{(t-1)} \\
\tilde{D}_{t}+\tilde{\beta} \cdot B_{(t-1)}, & \tilde{D}_{t}+\tilde{\beta} \cdot B_{(t-1)}<Q_{t} \\
& +(1-\tilde{\theta}) \cdot I_{(t-1)}
\end{array}\right.
\end{aligned}
$$

The linearization process of total sale is implemented in three steps. 
- Step 1: At this step, we define binary variables, $Y_{t}$ and non-negative variables $Q_{t}^{\prime}$ and $Q_{t}^{\prime \prime}$. By these variables, Eq. (21) is transformed into Eq. (22):

$$
\begin{aligned}
S_{t}= & Q_{t}^{\prime}+(1-\tilde{\theta}) \cdot I_{(t-1)} \cdot Y_{t}+\left(\tilde{D}_{t}+\tilde{\beta} \cdot B_{(t-1)}\right) \\
& .\left(1-Y_{t}\right) \quad \forall t
\end{aligned}
$$

where the following constraints must be added to the main model:

$$
\begin{aligned}
& Q_{t}^{\prime} \leq\left(\tilde{D}_{t}+\tilde{\beta} \cdot B_{(t-1)}-(1-\tilde{\theta}) \cdot I_{(t-1)}\right) \cdot Y_{t} \quad \forall t \\
& \left(\tilde{D}_{t}+\tilde{\beta} \cdot B_{(t-1)}-(1-\tilde{\theta}) \cdot I_{(t-1)}\right) \cdot\left(1-Y_{t}\right) \\
& \quad \leq Q_{t}^{\prime \prime} \leq M \cdot\left(1-Y_{t}\right) \quad \forall t \\
& Q_{t}^{\prime}+Q_{t}^{\prime \prime}=Q_{t} \quad \forall t .
\end{aligned}
$$

- Step 2: To transform the product terms $I_{(t-1)} \cdot Y_{t}$ and $B_{(t-1)} . Y_{t}$ (in Eqs. (22)-(24)) into linear terms, two non-negative variables $f_{t}$ and $w_{t}$ are introduced, where $f_{t}=I_{(t-1)} \cdot Y_{t}$ and $w_{t}=B_{(t-1)} \cdot Y_{t}$. Thus, Eqs. (22)-(24) are replaced by Eqs. (26)-(28) as follows:

$$
\begin{gathered}
S_{t}=Q_{t}^{\prime}+(1-\tilde{\theta}) \cdot f_{t}+\tilde{D}_{t} \cdot\left(1-Y_{t}\right)+\tilde{\beta} \cdot B_{(t-1)} \\
-\tilde{\beta} \cdot w_{t} \quad \forall t, \\
Q_{t}^{\prime} \leq \tilde{D}_{t} \cdot Y_{t}+\tilde{\beta} \cdot w_{t}-(1-\tilde{\theta}) \cdot f_{t} \quad \forall t, \quad(27) \\
\left(1-Y_{t}\right) \cdot \tilde{D}_{t}+\tilde{\beta} \cdot B_{(t-1)}-\tilde{\beta} \cdot w_{t}-(1-\tilde{\theta}) \\
\quad I_{(t-1)}+(1-\tilde{\theta}) \cdot f_{t} \leq Q_{t}^{\prime \prime} \leq M \cdot\left(1-Y_{t}\right) \quad \forall t .
\end{gathered}
$$

The non-linear equation $f_{t}=I_{(t-1)} . Y_{t}$ can also be replaced by the following two linear equations:

$$
\begin{aligned}
& -Y_{t} \cdot M \leq f_{t} \leq Y_{t} \cdot M \quad \forall t, \\
& I_{(t-1)}-\left(1-Y_{t}\right) \cdot M \leq f_{t} \leq I_{(t-1)}+\left(1-Y_{t}\right) \cdot M \quad \forall t .
\end{aligned}
$$

Equation $w_{t}=B_{(t-1)} \cdot Y_{t}$ is similarly substituted by linear Constraints (31) and (32):

$$
\begin{array}{ll}
-Y_{t} \cdot M \leq w_{t} \leq Y_{t} \cdot M \quad \forall n, & \\
B_{(t-1)}-\left(1-Y_{t}\right) \cdot M \leq w_{t} \leq B_{(t-1)}+\left(1-Y_{t}\right) \cdot M & \forall t .
\end{array}
$$

According to these two steps, the total sale at period $t, S_{t}$ can be stated as a linear expression (Eq. (26)). In this way, some extra variables $\left(Y_{t}, Q_{t}^{\prime}, Q_{t}^{\prime \prime}, f_{t}, w_{t}\right)$ and constraints (Eqs. (25)-(32)) are added into the main model.

The total revenue at period $t$ is indicated by $R_{t}$. It is obtained by selling price $(p r)$ times total sale $\left(S_{t}\right)$, i.e. $R_{t}=p r . S_{t}$. Thus, if the selling price of product $(p r)$ is a constant parameter, the total revenue at period $t\left(p r . S_{t}\right)$ is linear. However, in our problem, the selling price of product $(p r)$ is quantity-dependent following Eq. (1). Thus, the total revenue at period $t$ is as follows:

$$
R_{t}=p r . S_{t}=\left\{\begin{array}{lcc}
p r_{1} . S_{t} & S A_{0} \leq S_{t}<S A_{1} & \\
p r_{2} . S_{t} & S A_{1} \leq S_{t}<S A_{2} & \forall t \\
\cdots & \ldots & (33) \\
p r_{m} . S_{t} & S A_{m-1} \leq S_{t}<S A_{m}
\end{array}\right.
$$

where $S_{t}$ is expressed in Eq. (26). The next step is therefore defined to develop the equivalent linear expression for the above multiple-breakpoint total revenue function.

- Step 3: To formulate Eq. (33) as a linear expression, we define binary variables, $t_{t m}$ and nonnegative variables, $S L_{t m}$. Then, Constraints (34)(36) are added as follows:

$$
\begin{aligned}
& S A_{m-1} \cdot t_{t k} \leq S L_{t m} \leq S A_{m} \cdot t_{t m} \quad \forall m, t, \\
& S_{t}=\sum_{m} S L_{t m} \quad \forall t, \\
& \sum_{m} t_{t m}=1 \quad \forall t .
\end{aligned}
$$

The total revenue at period $t\left(R_{t}\right)$ can therefore be formulated as a linear expression, $R_{t}=$ $\sum_{m} p r_{m} . S L_{t m}$.

Another linearization process is related to disposal cost. As mentioned, the disposal cost of each unit of product follows a multiple-breakpoint function as stated in Eq. (2). The disposal cost can therefore become linear by using the technique applied in Step 3 of revenue linearization process. In this way, non-negative variables, $I L_{t p}$, and binary variables, $\alpha_{t p}$, are defined, where $t \in\{1, \ldots, T\}$ and $p \in\{1, \ldots, P\}$. Then, the following constraints should be added to the model:

$$
\begin{aligned}
& K_{p-1} \cdot \alpha_{t p} \leq \tilde{\theta} . I L_{t p} \leq K_{p} \cdot \alpha_{t p} \quad \forall p, t, \\
& I_{t}=\sum_{p} I L_{t p} \quad \forall t \\
& \sum_{p} \alpha_{t p}=1 \quad \forall t .
\end{aligned}
$$

In this way, the disposal cost of deteriorated onhand inventories can be stated by the linear expres- 
sion $\sum_{t} \sum_{p} S V_{p} \cdot \tilde{\theta} . I L_{t p}$. In a similar way, disposal cost of on-the-way inventories is stated by linear expressions. $\lambda_{t}$ represents on-the-way inventories deteriorated in period $t$, i.e. $\lambda_{t}=\sum_{v, f} \tilde{\eta} . \delta_{t v f}$. By defining binary variables, $\alpha_{t p}^{\prime}$, non-negative variables, $\lambda L_{t p}$, and Constraints (40)-(42), total disposal costs of on-the-way inventories can be stated as $\sum_{t} \sum_{p} S V_{p} \cdot \lambda L_{t p}$ :

$$
\begin{aligned}
& K_{p-1} \cdot \alpha_{t p}^{\prime} \leq \lambda L_{t p} \leq K_{p} \cdot \alpha_{t p}^{\prime} \quad \forall p, t, \\
& \lambda_{t}=\sum_{p} \lambda L_{t p} \quad \forall t \\
& \sum_{p} \alpha_{t p}^{\prime}=1 \quad \forall t .
\end{aligned}
$$

When an order is received by the retailer, nondeteriorated products are isolated from deteriorated ones. In this way, deteriorated on-the-way inventories are disposed at the beginning of the periods while disposing of deteriorated on-hand inventories is done at the end of each period. In other words, disposing of deteriorated on-the-way inventories and deteriorated on-hand products are is carried out at the same time. This is why we separate the linearization procedure of these two processes' costs. With some minor modifications, the developed mathematical model can also be applicable when these two processes are done concurrently.

Finally, the last non-linear expression in the mathematical model developed in Section 5.1. is related to $Z_{3}$ (Eq. (5)) including absolute terms. The term $\left|H U_{t}-H U_{(t-1)}\right|$ could be converted to a linear one with the help of two non-negative auxiliary variables $H U_{t}^{+}$and $H U_{t}^{-}$as follows:

$$
\left|H U_{t}-H U_{(t-1)}\right|=H U_{t}^{+}+H U_{t}^{-},
$$

s.t.

$$
H U_{t}-H U_{(t-1)}=H U_{t}^{+}-H U_{t}^{-} .
$$

Similarly, the term $\left|\sum_{f} X_{t v f}-\sum_{f} X_{(t-1) v f}\right|$ is converted to a linear expression by defining two auxiliary variables $X T_{t v}^{+} \geq 0$ and $X T_{t v}^{-} \geq 0$.

Consequently, the linear form of the developed model can be expressed as follows:

$$
\begin{aligned}
\operatorname{Max} Z_{1}= & \sum_{t, k} p r_{k} \cdot S_{t k}-\sum_{t>0}\left(O \cdot V_{t}+C \cdot \sum_{v, f} \delta_{t v f}\right. \\
& +h \cdot I_{t}+(1-\tilde{\beta}) \cdot \pi \cdot B_{t}+\tilde{\beta} \cdot \gamma \cdot B_{t} \\
& +\sum_{v, f}\left(T A_{v f} \cdot d_{f} \cdot X_{t v f}\right)+\sum_{p}\left(S V_{p} \cdot \tilde{\theta} \cdot I L_{t p}\right) \\
& \left.+\sum_{p}\left(S V_{p} \cdot \lambda L_{t p}\right)+C H_{t} \cdot H U_{t}\right),
\end{aligned}
$$

$$
\begin{array}{r}
\operatorname{Min} Z_{2}=\sum_{t>0}\left(\sum_{v, f}\left(G_{v f} \cdot d_{f} \cdot X_{t v f}\right)\right. \\
\left.+G D \cdot\left(\lambda_{t}+\tilde{\theta} \cdot I_{t}\right)\right),
\end{array}
$$

$$
\begin{aligned}
\operatorname{Min} Z_{3}= & \sum_{t}\left(H U_{t}^{+}+H U_{t}^{-}\right)+\sum_{t, v} H T_{v} \\
& .\left(X T_{t v}^{+}+X T_{t v}^{-}\right),
\end{aligned}
$$

s.t.

$Q_{t}+(1-\tilde{\theta}) \cdot I_{(t-1)}-\tilde{D}_{t}-\tilde{\beta} \cdot B_{(t-1)}=I_{t}-B_{t} \quad \forall t$

$B_{t} \leq M \cdot N_{t} \quad \forall t$

$I_{t} \leq M \cdot\left(1-N_{t}\right) \quad \forall t$

$\frac{V_{t}}{M} \leq Q_{t} \leq M \cdot V_{t} \quad \forall t$

$S_{t}=\sum_{m} S L_{t m} \quad \forall t$

$S A_{m-1} \cdot t_{t m} \leq S L_{t m} \leq S A_{m} \cdot t_{t m} \quad \forall m, t$,

$\sum_{m} t_{t m}=1 \quad \forall t$

$$
\begin{aligned}
S_{t}= & Q_{t}^{\prime}+(1-\tilde{\theta}) \cdot f_{t}+\tilde{D}_{t} \cdot\left(1-Y_{t}\right)+\tilde{\beta} \cdot B_{(t-1)} \\
& -\tilde{\beta} \cdot w_{t} \quad \forall t
\end{aligned}
$$

$$
Q_{t}^{\prime} \leq \tilde{D}_{t} \cdot Y_{t}+\tilde{\beta} \cdot w_{t}-(1-\tilde{\theta}) \cdot f_{t} \quad \forall t
$$

$$
\begin{gathered}
\left(1-Y_{t}\right) \cdot \tilde{D}_{t}+\tilde{\beta} \cdot B_{(t-1)}-\tilde{\beta} \cdot w_{t}-(1-\tilde{\theta}) \cdot I_{(t-1)} \\
+(1-\tilde{\theta}) \cdot f_{t} \leq Q_{t}^{\prime \prime} \leq M \cdot\left(1-Y_{t}\right) \quad \forall t,
\end{gathered}
$$$$
-Y_{t} \cdot M \leq f_{t} \leq Y_{t} \cdot M \quad \forall t,
$$

$I_{(t-1)}-\left(1-Y_{t}\right) \cdot M \leq f_{t} \leq I_{(t-1)}+\left(1-Y_{t}\right) \cdot M \quad \forall t$,

$-Y_{t} \cdot M \leq w_{t} \leq Y_{t} \cdot M \quad \forall t$

$B_{(t-1)}-\left(1-Y_{t}\right) \cdot M \leq w_{t} \leq B_{(t-1)}+\left(1-Y_{t}\right) \cdot M \quad \forall t$

$Q_{t}^{\prime}+Q_{t}^{\prime \prime}=Q_{t} \quad \forall t$

$K_{p-1} \cdot \alpha_{t p} \leq \tilde{\theta} \cdot I L_{t p} \leq K_{p} \cdot \alpha_{t p} \quad \forall p, t$ 


$$
\begin{aligned}
& I_{t}=\sum_{p} I L_{t p} \quad \forall t, \\
& \sum_{p} \alpha_{t p}=1 \quad \forall t \\
& K_{p-1} \cdot \alpha_{t p}^{\prime} \leq \lambda L_{t p} \leq K_{p} \cdot \alpha_{t p}^{\prime} \quad \forall p, t, \\
& \lambda_{t}=\sum_{p} \lambda L_{t p} \quad \forall t \\
& \sum_{p} \alpha_{t p}^{\prime}=1 \quad \forall t \\
& \lambda_{t}=\sum_{v, f} \tilde{\eta} \cdot \delta_{t v f} \quad \forall t \\
& H U_{t}-H U_{(t-1)}=H U_{t}^{+}-H U_{t}^{-} \quad \forall t, \\
& \sum_{f} X_{t v f}-\sum_{f} X_{(t-1) v f}=X T_{t v}^{+}-X T_{t v}^{-} \quad \forall t, v \\
& Q_{t}=\sum_{v, f}\left(1-\tilde{\eta}_{v f}\right) \cdot \delta_{t v f} \quad \forall t \\
& \left(H U_{t}-1\right) \leq \frac{\sum_{v, f} \delta_{t v f}}{H U M} \leq H U_{t} \quad \forall t, \\
& Q_{t v f} \leq C A P_{v} \cdot X_{t v f} \quad \forall t, f, v, \\
& \sum_{f} X_{t v f} \leq M A X T_{v} \quad \forall v, t \\
& X_{t v f}, H U_{t}, H U_{t}^{+}, H U_{t}^{-}, X T_{t v}^{+}, H T_{t v}^{-} \geq 0 \text {, integer } \\
& \forall t, v, f \text {, } \\
& N_{t}, V_{t}, Y_{t}, t_{t m}, \alpha_{t p}, \alpha_{t p}^{\prime} \in\{0,1\} \quad \forall t, m, p, \\
& Q_{t}, Q_{t}^{\prime}, Q_{t}^{\prime \prime}, \delta_{t v f}, \lambda_{t}, \lambda L_{t p}, I_{t}, I L_{t p}, B_{t}, S_{t}, S L_{t k}, \\
& f_{t}, w_{t} \geq 0 \quad \forall t, v, f, m, p .
\end{aligned}
$$

\section{Solution approach}

A possibilistic programming approach is taken to solve the mixed-integer linear model with fuzzy parameters developed in the previous sections. To develop the equivalent crisp model, we use the Jimenez et al. [44] method. A brief explanation of this method follows and interested readers are referred to Jimenez et al. [44] for more details.

Assume that $\tilde{a}=\left(a^{p}, a^{m}, a^{0}\right)$ shows a triangular fuzzy number. Then, the expected value $(E(\tilde{a}))$ and the expected interval $(I(\tilde{a}))$ of $\tilde{a}$ are respectively defined as follows:

$$
\begin{aligned}
& E(\tilde{a})=\frac{E_{1}^{a}+E_{2}^{a}}{2}=\frac{a^{p}+2 a^{m}+a^{0}}{4}, \\
& I(\tilde{a})=\left[E_{1}^{a}, E_{2}^{a}\right]=\left[\frac{1}{2}\left(a^{p}+a^{m}\right), \frac{1}{2}\left(a^{m}+a^{0}\right)\right] .
\end{aligned}
$$

Additionally, the mathematical model developed in the previous section can be presented by the following parametric multi-objective linear mathematical programming model, in which i) There are $H$ different objective functions, $Z_{1}, \ldots, Z_{H}$, and ii) All parameters are considered as triangular fuzzy numbers:

$$
\begin{aligned}
& \operatorname{Min} z_{1}=\tilde{c}_{1}^{t} x \\
& \ldots \\
& \text { Min } \quad Z_{H}=\tilde{c}_{H}^{t} x \\
& \text { t. } \\
& \tilde{a}_{i} x \geq \tilde{b}_{i}, \quad i=1, \ldots, l, \\
& \tilde{a}_{i} x=\tilde{b}_{i} \quad i=l+1, \ldots, l \\
& x \geq 0 .
\end{aligned}
$$$$
\text { s.t. }
$$

Based on Jimenez et al. [44] and the definition of the expected value and the expected interval of triangular fuzzy numbers presented in Eqs. (79) and (80), the equivalent crisp-parametric model of the above model (Eq. (81)) may be written as follows:

$$
\begin{aligned}
& \text { Min } z_{1}=E\left(\tilde{c}_{1}\right)^{t} \cdot x \\
& \ldots \\
& \text { Min } \quad Z_{H}=E\left(\tilde{c}_{H}\right)^{t} \cdot x
\end{aligned}
$$

s.t.

$$
\begin{aligned}
& {\left[(1-\alpha) E_{2}^{a_{i}}+\alpha E_{1}^{a_{i} x}\right]=x \geq \alpha E_{2}^{b_{i}}+(1-\alpha) E_{1}^{b_{i}}} \\
& \quad i=1, \ldots, l, \\
& {\left[\left(1-\frac{\alpha}{2}\right) E_{2}^{a_{i}}+\frac{\alpha}{2} E_{1}^{a_{i} x}\right] x \geq \frac{\alpha}{2} E_{2}^{b_{i}}+\left(1-\frac{\alpha}{2}\right) E_{1}^{b_{i}}} \\
& \quad i=l+1, \ldots, m \\
& {\left[\left(\frac{\alpha}{2}\right) E_{2}^{a_{i}}+\left(1-\frac{\alpha}{2}\right) E_{1}^{a_{i} x}\right] x \geq\left(1-\frac{\alpha}{2}\right) E_{2}^{b_{i}}+\frac{\alpha}{2} E_{1}^{b_{i}}} \\
& \quad i=l+1, \ldots, m \\
& x \geq 0
\end{aligned}
$$

where $\alpha$ shows feasibility degree of a solution. Finally, based on Selim and Ozkarahan [45], the auxiliary crisp multi-objective Mixed Integer Linear Programming (MILP) model is converted into an equivalent single-objective MILP model using the following new auxiliary crisp formulation: 
Table 3. Transportation vehicle's data.

\begin{tabular}{|c|c|c|c|c|c|c|c|c|}
\hline \multirow[b]{2}{*}{$V$} & \multirow[b]{2}{*}{$C A P_{v}$} & \multirow[b]{2}{*}{$M A X T_{v}$} & \multirow[b]{2}{*}{$H T_{v}$} & \multirow[b]{2}{*}{$T A_{v f}, f=1,2$} & \multicolumn{2}{|l|}{ Path 1} & \multicolumn{2}{|l|}{ Path 2} \\
\hline & & & & & $\tilde{\boldsymbol{\eta}}_{v 1}$ & $G_{v 1}$ & $\tilde{\eta}_{v 2}$ & $G_{v 2}$ \\
\hline 1 (Small) & 500 & 10 & 1 & 15 & $(0.06,0.08,0.1)$ & 75 & $(0.03,0.04,0.05)$ & 30 \\
\hline 2 (Medium) & 900 & 10 & 1 & 18 & $(0.06,0.08,0.1)$ & 115 & $(0.03,0.04,0.05)$ & 60 \\
\hline 3 (Large) & 1200 & 10 & 1 & 21 & $(0.06,0.08,0.1)$ & 123 & $(0.03,0.04,0.05)$ & 75 \\
\hline
\end{tabular}

$$
\operatorname{Max} \quad \chi \cdot \lambda_{0}+(1-\chi) \sum_{h} w_{h} \mu_{h}(x)
$$

s.t.

$$
\begin{aligned}
& \lambda_{0} \leq \mu_{h}(x) \quad h \in\{1, \ldots, H\} \\
& x \in F(x), \lambda_{0} \text { and } \quad \chi \in[0,1],
\end{aligned}
$$

where $w_{h}$ indicates relative importance of the $h$ th objective function; $F(x)$ denotes feasible region (area) involving crisp constrains in model (82).

Finally, by specifying the minimum and maximum amounts of each objective function separately, the linear membership function for each objective is defined as follows:

$$
\begin{aligned}
& \mu_{h}(x)= \\
& \begin{cases}1 & Z_{h}>Z_{h}^{\max } \\
\frac{Z_{h}-Z_{h}^{\min }}{Z_{h}^{\max }-Z_{h}^{\min }} & Z_{h}^{\min } \leq Z_{h} \leq Z_{h}^{\max } \\
0 & Z_{h}<Z_{h}^{\min }\end{cases}
\end{aligned}
$$

In Eq. (84), $Z_{h}^{\min }$ and $Z_{h}^{\max }$ show the minimum and maximum values of $Z_{h}$, respectively.

\section{Numerical analysis}

In the following, we apply the proposed model to a supply chain with a retailer, a fresh produce center in Tehran, Iran, and its supplier. A centralized decisionmaking process is applied in this supply chain. The planning horizon consists of three periods. Different levels of demand (optimistic, most likely, and pessimistic) at the first, second, and third periods are predicted as $(12000,13000,14000)$, (9000, 10000, 11000), and $(1600,1700,1800)$, respectively.

The ordering and purchasing costs are estimated as $A=€ 50000 /$ ordering and $C=€ 50 /$ unit, respectively. On average, one worker is required for supplying and purchasing 10 units of products, i.e. $H U M=10$. Since the cost of hiring a worker is tiny in comparison with other costs, without loss of generality, we consider $C H_{t}=0$. The selling price, $p r$, is as follows:

$$
p r= \begin{cases}300 & 0 \leq S_{t}<5000 \\ 280 & 5000 \leq S_{t}<10000 \\ 250 & 10000 \leq S_{t}\end{cases}
$$

The product deterioration rate is estimated by $\tilde{\theta}=$ $(0.03,0.05,0.07)$. GHG level produced by a unit of deteriorated product is estimated as $G D=60 \mathrm{gr} / \mathrm{unit}$. The retailer's initial inventory and initial shortage levels are $I_{0}=50$ and $B_{0}=0$ units, respectively.

There are two routes (paths) between supplier and retailer. The first route, called the "desert path", passes through a hot and dry zone while the second route passes through a forest area. The second route is called the "green path", since a significant portion of GHG emissions produced by the transportation vehicles is refined and dissipated by the plants. However, the green path is longer and more expensive than the desert one. The length of the desert path is $15 \mathrm{~km}$ while the green path is about $30 \%$ longer $(20 \mathrm{~km})$.

Three types of vehicles (small, medium, and large) are available for transferring orders. Information on the transportation vehicle is summarized in Table 3.

According to Table 3, due to climate conditions, deterioration rate of products is higher in Path 1 than in Path 2.

In each period, based on total supply (quantity ordered as well as uncertain remaining inventory from the previous period) and requirements (uncertain backordered demands as well as new uncertain demands), three situations may take place:

(i) Requirement is less than supply, i.e. the inventory level is positive and shortage is zero at the end of the period. In this case, $\tilde{\theta}$ percent of the remaining inventory is deteriorated with a cost of SV:

$$
S V= \begin{cases}30 & 0 \leq \text { disposal quantity }<100 \\ 25 & 100 \leq \text { disposal quantity }<200 \\ 10 & 200 \leq \text { disposal quantity }\end{cases}
$$

The rest of the inventories are stocked, up to the next period, with a cost of $h=5 € /$ unit;

(ii) Requirement is more than supply, which implies that inventory and shortage levels are zero and positive, respectively, at the end of the period. In this case, $\tilde{\beta}=(0.03,0.05,0.07)$ of unfulfilled demands is backordered and transferred to the next period with a cost of $\gamma=10 € /$ unit. The rest is regarded as lost sales with a cost of $\pi=100 € /$ unit; 
Table 4. Optimal decision variables and objective functions.

\begin{tabular}{|c|c|c|c|c|c|c|c|c|c|c|c|}
\hline$w_{1}$ & $\boldsymbol{w}_{2}$ & $w_{3}$ & $Q_{1}$ & $Q_{2}$ & $Q_{3}$ & $X_{1}$ & $X_{2}$ & $\boldsymbol{X}_{\mathbf{3}}$ & $Z_{1}$ & $Z_{2}$ & $Z_{3}$ \\
\hline 1 & 0 & 0 & 12950 & 11771 & 0 & {$[0,3,9][0,0,0]$} & {$[0,3,8][0,0,0]$} & {$[0,0,0][0,0,0]$} & 5144276 & 107830 & 2721 \\
\hline 0.6 & 0.2 & 0.2 & 9950 & 9970 & 1719 & {$[0,0,0][4,0,7]$} & {$[0,0,0][4,0,7]$} & {$[0,0,0][0,1,1]$} & 4504656 & 82704 & 1925 \\
\hline
\end{tabular}

Table 5. The objective functions' components.

\begin{tabular}{|c|c|c|c|c|c|c|c|c|c|c|c|c|}
\hline & \multicolumn{8}{|c|}{$Z_{1}$} & \multicolumn{2}{|c|}{$Z_{2}$} & \multicolumn{2}{|c|}{$Z_{3}$} \\
\hline & $\boldsymbol{R}$ & BC & $\mathbf{L C}$ & $\mathrm{HC}$ & OC & PC & DC & TC & GHG-D & GHG-T & HT & HS \\
\hline$w_{1}=1, w_{2}=w_{3}=0$ & 6560000 & 0 & 0 & 8856 & 100000 & 1287600 & 12293 & 6975 & 66115 & 41715 & 24 & 2697 \\
\hline$w_{1}=0.6, w_{2}=w_{3}=0.2$ & 6104300 & 1590 & 302100 & 50 & 150000 & 1127100 & 9744.4 & 9060 & 54204 & 28500 & 30 & 1898 \\
\hline
\end{tabular}

Note: R: Total revenue; BC: Backorder Cost; LC: Lost-sale Cost; HC: Holding Cost; OC: Ordering Cost;

PC: Procurement Cost; DC: Disposal Cost; TC: Expected transportation cost;

GHG-D: GHG emission produced by deterioration; GHG-T: GHG emission produced by transportation;

HT: Variations in required labor for transportation; HS: Variations in required labor for supplying product;

(iii) Requirement is equal to supply, which means no shortage or inventory exists at the end of the period.

All computations were run applying the CPLEX algorithm accessed via IBM ILOG CPLEX 12.2 on a PC Core (TM) i5 -2.3 GHz and 4.00 GB RAM under Windows 7 Home Premium.

In Table 4, the optimal value of the objective function is reported for two cases: i) first, the model is solved merely by considering the economic aspect, i.e. $w_{1}=1$ and $w_{2}=w_{3}=0$; ii) then, by changing the relative weights $\left(w_{1}=0.6, w_{2}=w_{3}=0.2\right)$, the optimal values of decision variables are obtained by taking into account economic $\left(Z_{1}\right)$, environmental $\left(Z_{2}\right)$, and social $\left(Z_{3}\right)$ aspects. The optimal values of the objective function components are reported in Table 5 for these two cases.

In Table 4, the optimal configuration of the vehicles in each period is reported as a symbol consisting of 2 vectors, each one showing the number of vehicles of each type used in each path. For example, when $w_{1}=1, w_{2}=w_{3}=0, X_{1}^{*}=\left[\begin{array}{lll}0 & 3 & 9\end{array}\right]\left[\begin{array}{lll}0 & 0 & 0\end{array}\right]$ denotes that in the first period, three vehicles of type 2 and nine vehicles of type 3 are used in Path 1 (desert path) while no vehicle is used in Path 2 (green path).

As Table 4 shows, when $w_{1}=1$ and $w_{2}=w_{3}=$ 0 , the highest value for $Z_{1}^{*}$ is $5,144,300$. Whereas the worst values for GHGs emissions $\left(Z_{2}^{*}\right)$ and labor variations $\left(Z_{3}^{*}\right)$ are obtained in this state.

When the Decision Maker (DM) is concerned with environmental and social criteria as much as costs $\left(w_{1}=0.6\right.$, and $\left.w_{2}=w_{3}=0.2\right)$, the optimal values of the objective functions and decision variables are considerably modified. As Table 4 shows, by considering $Z_{2}$ and $Z_{3}$ in addition to $Z_{1}$ (an SSC), the system loses a part of the profit in comparison with a state that only regards the economic objective (an economic supply chain). According to Table 4, the environmental and social objectives are improved by about $23.3 \%$ and $29.25 \%$, respectively, by losing about $12.4 \%$ of total profit.

Considering sustainability criteria, optimal inventory and transportation policy and transportation paths are changed. As well, when the DM switches from an economic supply chain to a sustainable one, optimal values of order quantities are more homogeneous through the planning horizon. Some reasons for this event are i) maintaining variations in the required labor as minimum as possible, and ii) reducing $\mathrm{GHG}$ emission as well as costs related to the deterioration process. Values of disposal costs and their related GHGs confirm this statement in Table 5.

\section{Sensitivity analysis}

In this section, a sensitivity analysis is done regarding the weight (importance) of the objective function. For this purpose, the numerical analysis is done in three stages:

i) Just economic and environmental criteria $\left(Z_{1}\right.$ and $Z_{2}$ ) are considered;

ii) Just economic and social criteria $\left(Z_{1}\right.$ and $\left.Z_{3}\right)$ are considered; and

iii) All economic, environmental, and social criteria $\left(Z_{1}, Z_{2}\right.$ and $\left.Z_{3}\right)$ are considered.

In the first step, we take into account just economic and environmental criteria (a green supply chain). Thus, $w_{3}=0$ and $w_{2}=1-w_{1}$. The obtained results are reported in Table 6 and the Pareto solutions are presented in Figure 2.

According to Table 6 and Figure 2, whenever $w_{1}$ decreases (the weight of GHG criteria $\left(1-w_{1}\right)$ increases), lost profit and GHG reduction percentages 
Table 6. Optimal decision variables and objective functions considering economic and environmental criteria, $w_{2}=1-w_{1}$.

\begin{tabular}{|c|c|c|c|c|c|c|c|c|c|c|}
\hline$w_{1}$ & $Q_{1}$ & $Q_{2}$ & $Q_{3}$ & $X_{1}$ & $X_{2}$ & $X_{3}$ & $z_{1}$ & $z_{2}$ & $\begin{array}{c}\text { Lost } \\
\text { profit } \\
(\%)\end{array}$ & $\begin{array}{c}\text { GHG } \\
\text { reduction } \\
(\%)\end{array}$ \\
\hline 1 & 12950 & 11771 & 0 & {$[0,3,9][0,0,0]$} & {$[0,3,8][0,0,0]$} & {$[0,0,0][0,0,0]$} & 5144276 & 107830 & - & - \\
\hline 0.9 & 12950 & 11789 & 0 & {$[0,0,0][4,1,9]$} & {$[0,0,0][8,0,7]$} & {$[0,0,0][0,0,0]$} & 5139400 & 98655 & 0.1 & 8.5 \\
\hline 0.8 & 12950 & 10071 & 1632 & {$[0,0,0][3,0,10]$} & {$[0,0,0][9,0,5]$} & {$[0,0,0][1,0,1]$} & 5104600 & 93651 & 0.8 & 13.1 \\
\hline 0.7 & 12950 & 10071 & 1632 & {$[0,0,0][3,0,10]$} & {$[0,0,0][9,0,5]$} & {$[0,0,0][1,0,1]$} & 5104600 & 93651 & 0.8 & 13.1 \\
\hline 0.6 & 12864 & 10000 & 1632 & {$[0,0,0][10,0,7]$} & {$[0,0,0][9,0,5]$} & {$[0,0,0][1,0,1]$} & 5055400 & 92760 & 1.7 & 14.0 \\
\hline 0.5 & 9792 & 9984 & 1632 & {$[0,0,0][6,0,6]$} & {$[0,0,0][4,0,7]$} & {$[0,0,0][1,0,1]$} & 4432300 & 81120 & 13.8 & 24.8 \\
\hline $0.1-0.4$ & 0 & 0 & 0 & - & - & - & -2451800 & 0 & - & - \\
\hline
\end{tabular}

Table 7. Optimal decision variables and objective functions considering economic and social criteria, $w_{3}=1-w_{1}$.

\begin{tabular}{|c|c|c|c|c|c|c|c|c|c|c|}
\hline$w_{1}$ & $Q_{1}$ & $Q_{2}$ & $Q_{3}$ & $X_{1}$ & $\boldsymbol{X}_{2}$ & $\boldsymbol{X}_{3}$ & $z_{1}$ & $z_{2}$ & $\begin{array}{c}\text { Lost } \\
\text { profit }(\%)\end{array}$ & $\begin{array}{c}\text { Reductionin } \\
\text { labor } \\
\text { variations (\%) }\end{array}$ \\
\hline 1 & 12950 & 11771 & 0 & {$[0,3,9][0,0,0]$} & {$[0,3,8][0,0,0]$} & {$[0,0,0][0,0,0]$} & 5144276 & 2721 & - & - \\
\hline 0.9 & 12950 & 10000 & 1700 & {$[0,3,9][0,0,0]$} & {$[0,1,8][0,0,0]$} & {$[0,1,8][0,0,0]$} & 5106600 & 2535 & 0.7 & 6.8 \\
\hline 0.8 & 9950 & 10000 & 9587 & {$[0,3,9][0,0,0]$} & {$[0,3,9][0,0,0]$} & {$[0,3,9][0,0,0]$} & 4626400 & 1667 & 10.1 & 38.7 \\
\hline 0.7 & 9950 & 9990 & 9568 & {$[0,1,8][0,0,0]$} & {$[0,1,8][0,0,0]$} & {$[0,1,8][0,0,0]$} & 4036100 & 1050 & 21.5 & 61.4 \\
\hline 0.6 & 9950 & 9990 & 9568 & {$[0,1,8][0,0,0]$} & {$[0,1,8][0,0,0]$} & {$[0,1,8][0,0,0]$} & 4036100 & 1050 & 21.5 & 61.4 \\
\hline 0.5 & 9950 & 9950 & 9534 & {$[0,1,8][0,0,0]$} & {$[0,1,8][0,0,0]$} & {$[0,1,8][0,0,0]$} & 4025900 & 1046 & 21.7 & 61.6 \\
\hline 0.4 & 9950 & 9950 & 9534 & {$[0,1,8][0,0,0]$} & {$[0,1,8][0,0,0]$} & {$[0,1,8][0,0,0]$} & 4025900 & 1046 & 21.7 & 61.6 \\
\hline 0.3 & 2121 & 2121 & 2120 & {$[0,0,2][0,0,0]$} & {$[0,0,2][0,0,0]$} & {$[0,0,2][0,0,0]$} & -400810 & 0223 & 147.7 & 91.8 \\
\hline $0.1-0.2$ & 0 & 0 & 0 & - & - & - & -2451800 & 0 & - & - \\
\hline
\end{tabular}

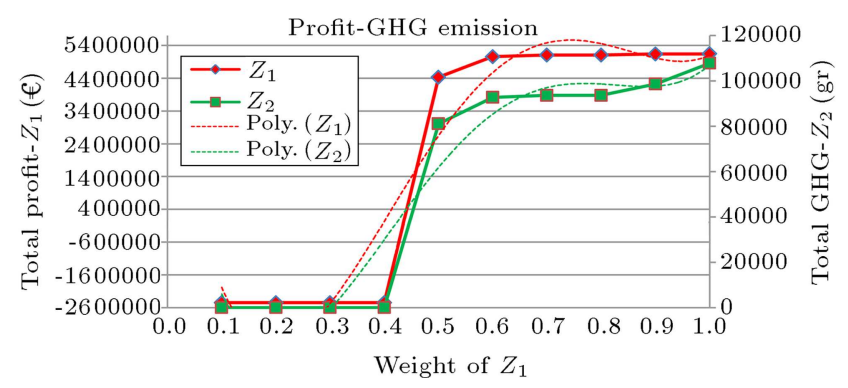

Figure 2. Optimal total profit against the optimal GHG emissions.

increase. In this way, when the importance factor (weight) of the green criteria is more than 0.5 , purchasing is not sound and the supply chain has to be brought to a close. However, in some cases, an acceptable reduction in GHGs emissions is reachable with just a minor reduction in total profit. For example, when $w_{1}=0.7$ and $w_{2}=0.3$, about $13 \%$ GHG reduction can be obtained with less than $1 \%$ reduction in total profit. Besides, as Table 6 shows, when DM is concerned with the environmental criterion, the "green path" is the preferable one even though it is longer and more costly than the other path.
Table 7 presents optimal policies with attention to the economic and social criteria and disregarding the environmental aspect. Thus, $w_{2}=0$ and $w_{3}=1-w_{1}$. Here, green criteria are not concerned $\left(w_{2}=0\right)$. In all cases, Path 1 (desert path) is therefore the optimal path because it is shorter and more cost-effective.

Moreover, in some periods, an extra cost may be incurred for holding extra equipment whenever variations of required labors are important. For example, when $w_{1}=0.9\left(w_{3}=0.1\right)$, the optimal values of order quantities are determined as $Q_{1}=12950, Q_{2}=10000$, and $Q_{3}=1700$. However, at $Q_{3}=1700$, the optimal transportation vehicles are more than the required ones in the third period (a type- 2 vehicle (capacity: 900) and eight type-3 vehicles (capacity: 1200)). In fact, to make variations of labors as low as possible, the supply chain is forced to have extra transportation vehicles in period 3, considering required labors in the first and second periods.

In addition, since the capacity of vehicle type3 is more than the others, the system prefers to use vehicle type- 3 more as the weight of $Z_{3}$ increases. In fact, by having high-capacity vehicles, the number of required vehicles for transferring order quantities 
Table 8. Optimal decision variables and objective functions with economic, environmental, and social criteria.

\begin{tabular}{|c|c|c|c|c|c|c|c|c|c|c|c|}
\hline$w_{1}$ & $w_{2}$ & $w_{3}$ & $Q_{1}$ & $Q_{2}$ & $Q_{3}$ & $X_{1}$ & $X_{2}$ & $X_{3}$ & $z_{1}$ & $z_{2}$ & $z_{3}$ \\
\hline 1 & 0 & 0 & 12950 & 11771 & 0 & {$[0,3,9][0,0,0]$} & {$[0,3,8][0,0,0]$} & {$[0,0,0][0,0,0]$} & 5144276 & 107830 & 2721 \\
\hline 0.9 & 0.05 & 0.05 & 12950 & 10000 & 1700 & {$[0,0,0][0,3,10]$} & {$[0,0,0][2,0,8]$} & {$[0,0,0][2,1,0]$} & 5104400 & 94080 & 2545 \\
\hline 0.8 & 0.1 & 0.1 & 12950 & 10000 & 1700 & {$[0,0,0][0,3,10]$} & {$[0,0,0][2,0,8]$} & {$[0,0,0][2,1,0]$} & 5104400 & 94080 & 2545 \\
\hline 0.7 & 0.15 & 0.15 & 9950 & 9984 & 1708 & {$[0,0,0][4,0,7]$} & {$[0,0,0][4,0,7]$} & {$[0,0,0][4,0,0]$} & 4508400 & 82380 & 1919 \\
\hline 0.6 & 0.2 & 0.2 & 9950 & 9970 & 1719 & {$[0,0,0][4,0,7]$} & {$[0,0,0][4,0,7]$} & {$[0,0,0][0,1,1]$} & 4504656 & 82704 & 1928 \\
\hline 0.5 & 0.25 & 0.25 & 4896 & 4896 & 1968 & {$[0,0,0][3,0,3]$} & {$[0,0,0][3,0,3]$} & {$[0,0,0][0,1,1]$} & 1474800 & 44700 & 826 \\
\hline 0.4 & 0.3 & 0.3 & 2112 & 2112 & 2112 & {$[0,0,0][2,0,1]$} & {$[0,0,0][2,0,1]$} & {$[0,0,0][2,0,1]$} & -412650 & 23940 & 223 \\
\hline $1 / 3$ & $1 / 3$ & $1 / 3$ & 0 & 0 & 0 & {$[0,0,0][0,0,0]$} & {$[0,0,0][0,0,0]$} & {$[0,0,0][0,0,0]$} & -2451800 & 0 & 0 \\
\hline
\end{tabular}

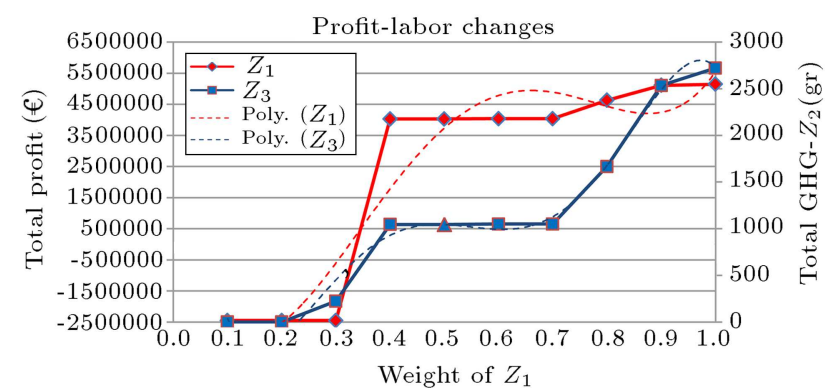

Figure 3. Optimal total profit against the optimal labor variations.

in different periods with various values will decrease. In other words, a high-capacity vehicle is able to transfer high and low quantities in different periods. Consequently, variations of the required labor for transportation will decrease through the planning horizon. Pareto solutions regarding $Z_{1}$ and $Z_{3}$ are presented in Figure 3.

Finally, Table 8 shows the optimal values of decision variables by considering all three objective functions. As this table shows, if DMs put very high values to social and environmental criteria, the supply chain loses its profitability. However, managers can play a positive role in improving social and environmental indices with just a minor cost (or lost profit).

For example, if the managers set $w_{1}=0.9$, $w_{2}=0.05$, and $w_{3}=0.05$, with less than $1 \%$ reduction in total profit, $12.8 \%$ and $6.5 \%$ improvements will be obtained regarding environmental and social criteria, respectively. This lost profit will be compensated in the medium- and long-term horizons by higher satisfaction, motivation, and, consequently, efficiency of workers. In other words, when the workers' sense of belonging and loyalty to their work rise ( $w_{3}$ increases), their creativity and efficiency consequently improve. Finally, with fewer employees and, thus, fewer costs, goals and mission of the organization can be accomplished.

\section{Conclusion}

Deterioration of products is a major concern in SCM, since most products decrease in quality or value during their life cycle. Deterioration is a non-linear function made up of many factors such as transportation types. The distinct feature of this research is that it is based on numerous characteristics of real deteriorating products and simultaneously considers all 3 sustainability dimensions in deteriorating products SCM.

This paper considered a centralized forward supply chain for a deteriorating product with various transportation options. Some variables such as the end-customer demand, the partial backordered ratio, and the deterioration rate were assumed to be uncertain. The two sources of deterioration were assumed to be: i) deterioration of in-stock inventories, and ii) deterioration of in-transit products, influenced by both transportation vehicles and transportation paths/modes. The vehicle types (or paths) had a considerable influence on transportation cost of each product, amount of GHG emission, and deterioration rate of product. A possibilistic mathematical model was developed to determine the optimal replenishment policy, transportation routes, and type of vehicles. It was solved after linearization of various expressions and constraints. The final solutions were illustrated using a fresh produce center in Tehran, Iran. The results show that DMs can manage green and social issues with a minor reduction in profits. Thus, managers may use what-if simulation to see the effects of higher economic and social values of their profitability.

The proposed model is certainly not inclusive and final, and further research is needed in the following respects:

i) Considering dependency of path and vehicles to the lead-time;

ii) Considering the accident risk related to features of vehicles and paths;

iii) Expanding the proposed model by considering more detailed reverse logistic processes; and

iv) Including multiple suppliers and multiple products. 


\section{Acknowledgment}

This work was supported by Iran National Science Foundation.

\section{References}

1. Sepehri, M. "Cost and inventory benefits of cooperation in multi-period and multi-product supply", Sci. Iran., 18(3), pp. 731-741 (2011).

2. Mirzapour Al-e-hashem, S.M.J., Baboli, A. and Sazvar, Z. "A stochastic aggregate production planning model in a green supply chain: Considering flexible lead times, nonlinear purchase and shortage cost functions", Eur. J. Oper. Res., 230(1), pp. 26-41 (2013).

3. Devika, K., Jafarian, A. and Nourbakhsh, V. "Designing a sustainable closed-loop supply chain network based on triple bottom line approach: A comparison of metaheuristics hybridization techniques", Eur. J. Oper. Res., 235(3), pp. 594-615 (2014).

4. Moretti, S., Zeynep Alparslan Gök, S., Branzei, R. and Tijs, S. "Connection situations under uncertainty and cost monotonic solutions", Comput. Oper. Res., 38(11), pp. 1638-1645 (2011).

5. Pishvaee, M.S. and Torabi, S.A. "A possibilistic programming approach for closed-loop supply chain network design under uncertainty", Fuzzy Sets Syst., 161(20), pp. 2668-2683 (2010).

6. Sazvar, Z., Mirzapour Al-e-hashem, S.M.J., Baboli, A. and Akbari Jokar, M.R. "A bi-objective stochastic programming model for a centralized green supply chain with deteriorating products", Int. J. Prod. Econ., 150, pp. 140-154 (2014).

7. Tsao, Y.-C. "Replenishment policies considering trade credit and logistics risk", Sci. Iran., 18(3), pp. 753-758 (2011).

8. World Commission on Environment and Development, Our Common Future, Oxford University Press, Oxford, UK (1987).

9. Wood, D.J. "Corporate social performance revisited", Acad. Manage. Rev., 16(4), pp. 691-718 (1991).

10. Ahi, P. and Searcy, C. "Assessing sustainability in the supply chain: A triple bottom line approach", Appl. Math. Model., 39(10-11), pp. 2882-2896 (2015).

11. Morali, O. and Searcy, C. "A review of sustainable supply chain management practices in Canada", $J$. Bus. Ethics, 117(3), pp. 635-658 (2012).

12. Seuring, S. "A review of modeling approaches for sustainable supply chain management", Decis. Support Syst., 54(4), pp. 1513-1520 (2013).

13. Brandenburg, M., Govindan, K., Sarkis, J. and Seuring, S. "Quantitative models for sustainable supply chain management: Developments and directions", Eur. J. Oper. Res., 233(2), pp. 299-312 (2014).

14. Ramezani, M., Bashiri, M. and Tavakkoli-Moghaddam, R. "A new multi-objective stochastic model for a forward/reverse logistic network design with responsiveness and quality level", Appl. Math. Model., 37(1), pp. 328-344 (2013).

15. Das, K. and Rao Posinasetti, N. "Addressing environmental concerns in closed loop supply chain design and planning", Int. J. Prod. Econ., 163, pp. 34-47 (2015).

16. Ghare, P.M. and Schrader., G.F. "A model for exponentially decaying inventory", J. Ind. Eng., 14(5), pp. 238-243 (1963).

17. Goyal, S.K. and Giri, B.C. "Recent trends in modeling of deteriorating inventory", Eur. J. Oper. Res., 134(1), pp. 1-16 (2001).

18. Amorim, P., Günther, H.-O. and Almada-Lobo, B. "Multi-objective integrated production and distribution planning of perishable products", Int. J. Prod. Econ., 138(1), pp. 89-101 (2012).

19. Prastacos, G.P. "Blood inventory management: an overview of theory and practice", Manag. Sci., 30(7), pp. 777-800 (1984).

20. Validi, S., Bhattacharya, A. and Byrne, P.J. "A case analysis of a sustainable food supply chain distribution system-A multi-objective approach", Int. J. Prod. Econ., 152, pp. 71-87 (2014).

21. Pishvaee, M.S., Razmi, J. and Torabi, S.A. "Robust possibilistic programming for socially responsible supply chain network design: A new approach", Fuzzy Sets Syst., 206, pp. 1-20 (2012).

22. Wang, F., Lai, X. and Shi, N. "A multi-objective optimization for green supply chain network design", Decis. Support Syst., 51(2), pp. 262-269 (2011).

23. El-Sayed, M., Afia, N. and El-Kharbotly, A. "A stochastic model for forward-reverse logistics network design under risk", Comput. Ind. Eng., 58(3), pp. 423431 (2010).

24. Jamshidi, R., Fatemi Ghomi, S.M.T. and Karimi, B. "Multi-objective green supply chain optimization with a new hybrid memetic algorithm using the Taguchi method", Sci. Iran., 19(6), pp. 1876-1886 (2012).

25. Bakker, M., Riezebos, J. and Teunter, R.H. "Review of inventory systems with deterioration since 2001", Eur. J. Oper. Res., 221(2), pp. 275-284 (2012).

26. Kim, T., Glock, C.H. and Kwon, Y. "A closed loop supply chain for deteriorating products under stochastic container returntimes", Omega, 43, pp. 3040 (2014).

27. Misra, S.K., Huang, C.L. and Ott, S.L. "Consumer willingness to pay for pesticide-free fresh produce", West. J. Agric. Econ., 16(2), pp. 218-227 (1991).

28. Fearne, A. and Hughes, D. "Success factors in the fresh produce supply chain: insights from the UK", Supply Chain Manag. Int. J., 4(3), pp. 120-131 (1999).

29. Blackburn, J. and Scudder, G. "Supply chain strategies for perishable products: The case of fresh produce", Prod. Oper. Manag., 18(2), pp. 129-137 (2009). 
30. Ferguson, M., Jayaraman, V. and Souza, G.C. "Note: An application of the EOQ model with nonlinear holding cost to inventory management of perishables", Eur. J. Oper. Res., 180(1), pp. 485-490 (2007).

31. Shukla, M. and Jharkharia, S. "Agri-fresh produce supply chain management: a state-of-the-art literature review", Int. J. Oper. Prod. Manag., 33(2), pp. 114158 (2013).

32. Sazvar, Z., Baboli, A. and Jokar, M.R.A. "A replenishment policy for perishable products with non-linear holding cost under stochastic supply lead time", Int. J. Adv. Manuf. Technol, 64(5-8), pp. 1087-1098 (2012).

33. Wang, K.-J., Lin, Y.S. and Yu, J.C.P. "Optimizing inventory policy for products with time-sensitive deteriorating rates in a multi-echelon supply chain", Int. J. Prod. Econ., 130(1), pp. 66-76 (2011).

34. Wee, H.M., Lee, M.-C., Yu, J.C.P. and Wang, C.E. "Optimal replenishment policy for a deteriorating green product: Life cycle costing analysis", Int. J. Prod. Econ., 133, pp. 603-611 (2011).

35. He, Y., Wang, S.-Y. and Lai, K.K. "An optimal production-inventory model for deteriorating items with multiple-market demand", Eur. J. Oper. Res., 203(3), pp. 593-600 (2010).

36. Wee, H.-M. and Chung, C.-J. "Optimising replenishment policy for an integrated production inventory deteriorating model considering green component-value design and remanufacturing", Int. J. Prod. Res., 47(5), pp. 1343-1368 (2009).

37. Liao, J.-J. "An EOQ model with noninstantaneous receipt and exponentially deteriorating items under two-level trade credit", Int. J. Prod. Econ., 113(2), pp. 852-861 (2008).

38. Urban, T.L. "An extension of inventory models with discretely variable holding costs", Int. J. Prod. Econ., 114(1), pp. 399-403 (2008).

39. Dye, C.-Y. "Joint pricing and ordering policy for a deteriorating inventory with partial backlogging", Omega, 35(2), pp. 184-189 (2007).

40. Mahata, G.C. and Goswami, A. "An EOQ model for deteriorating items under trade credit financing in the fuzzy sense", Prod. Plan. Control, 18(8), pp. 681-692 (2007).

41. Dye, C.-Y. and Ouyang, L.-Y. "An EOQ model for perishable items under stock-dependent selling rate and time-dependent partial backlogging", Eur. J. Oper. Res., 163(3), pp. 776-783 (2005).

42. Luo, W. "An integrated inventory system for perishable goods with backordering", Comput. Ind. Eng., 34(3), pp. 685-693 (1998).

43. Weiss, H.J. "Economic order quantity models with nonlinear holding costs", Eur. J. Oper. Res., 9(1), pp. 56-60 (1982).

44. Jimenez, M., Arenas, M., Bilbao, A. and Rodrıǵuez, M.V. "Linear programming with fuzzy parameters: an interactive method resolution", Eur. J. Oper. Res., 177, pp. 1599-1609 (2007).

45. Selim, H. and Ozkarahan, I. "A supply chain distribution network design model: an interactive fuzzy goal programming-based solution approach", Int. J. Adv. Manuf. Technol., 36, pp. 401-418 (2008).

\section{Biographies}

Mehran Sepehri is Associate Professor of Management and Economics at Sharif University of Technology, with current research interests in operations management, supply chain, and logistics. He received a $\mathrm{PhD}$ in Industrial Engineering and Engineering Management from Stanford University, with previous graduate work at MIT, and a BS degree in Industrial Engineering from Sharif University of Technology. He has 30 years of academic and industrial experience, in USA and Iran, in areas of project management, supply chain management, operation planning, and information systems.

Zeinab Sazvar is Assistant Professor at School of Industrial Engineering at Tehran University. She was a Post-Doc researcher in Graduate School of Management and Economics at Sharif University of Technology. She received her BSc and MSc degrees in Industrial Engineering from Sharif University of Technology (SUT), Iran, in 2006 and 2008, respectively. She is currently a PhD student in Industrial Engineering at SUT, Iran, and in Informatics and Mathematics at INSA Lyon, National Institute of Applied Sciences, France. Her current research interests include supply chain management, inventory control, revenue management, and operation research. 